\title{
La obra de Pablo Nin y González: dibujar la República para mostrarla al mundo
}

\author{
The work of Pablo Nin y González: drawing the Republic \\ to show it to the world \\ Daniela Tomeo \\ Instituto de Profesores Artigas/Consejo de Formación en Educación/ \\ Administración Nacional de Enseñanza Pública \\ Uruguay
}

DOI: https://doi.org/10.25032/crh.v7i12.3

Recibido: $30 / 3 / 2021$

Aceptado: 16/6/2021

Resumen: El calígrafo Pablo Nin y González integró una generación de uruguayos ocupados por la construcción de "lugares de memoria" que acompañaran la construcción del nuevo estado. En un país en el que las Bellas Artes entendidas en un sentido académico estaban apenas iniciando su camino, la realización de caligrafías referidas a personajes públicos, hechos históricos o alegorías de la patria, produjo una discreta pero interesante producción. La obra de Nin y González, La República Oriental del Uruguay, Libre, Independiente y Constituida, fue enviada por el artista en 1867 a la Exposición Universal de París y fue la única producción iconográfica que integró varios de los envíos oficiales a sucesivas exposiciones internacionales. El artículo presenta al calígrafo Pablo Nin González y a su obra en un contexto de producción de iconografías republicanas, que apuntaron a la construcción de un imaginario nacional y a la proyección de Uruguay como un país moderno y civilizado en el exterior.

Palabras clave: caligrafía, exposiciones universales, Uruguay, siglo XIX

\begin{abstract}
The calligrapher Pablo Nin y González was part of a generation of Uruguayans occupied by the construction of "places of memory" that would accompany the construction of the new state. In a country where the Fine Arts
\end{abstract}


understood in an academic sense were just beginning their way, the realization of calligraphies referring to public figures, historical events or allegories of the country, produced a discreet but interesting work. The work of Nin and González, La República Oriental del Uruguay, Libre, Independiente y Constituida, was sent by the artist in 1867 to the Universal Exhibition in Paris and was the only iconographic production that included several of the official shipments to successive international exhibitions. The article presents the calligrapher Pablo Nin González and his work in a context of the production of republican iconographies, which aimed at the construction of a national imaginary and the projection of Uruguay as a modern and civilized country abroad.

Keywords: calligraphy, universal exhibitions, Uruguay, $19^{\text {th }}$ Century.

\section{Introducción}

Las noveles repúblicas americanas que iniciaron sus vidas independientes en las primeras décadas del siglo XIX produjeron una serie de imágenes en los más variados soportes con la intención de acompañar la construcción de una buscada identidad nacional. Si bien las naciones eran nuevas, el uso de imágenes tendientes a construir un imaginario sobre la nación, tenía una larga tradición en el mundo occidental. La revolución francesa desplegó un repertorio de imágenes y símbolos que resignificaron en muchos casos los usos que el Antiguo Régimen había dado a la producción visual (Shiner 2004; Gombrich 2011). En nuestro país ha sido extensamente estudiada la obra de Juan Manuel Blanes, ${ }^{1}$ como creador de una iconografía que acompañó la construcción del novel estado en busca de una identidad nacional (Peluffo Linari 2000; Peluffo Linari y otros 2001, Malosetti Costa, 1995). ${ }^{2}$ Blanes fue sin duda un pintor mayor, de proyección regional, que de alguna manera dominó el escenario plástico uruguayo del siglo XIX. Sin embargo, si atendemos otras

\footnotetext{
1 Juan Manuel Blanes (1830-1901), formado con Manuel Besnes e Irigoyen viajó a Italia a completar su formación en la Academia de Florencia con el maestro Antonio Ciseri. Su obra cubrió distintos géneros, destacando en su producción las pinturas históricas, a las que el asignaba mayor valor.

${ }^{2}$ El proceso de construcción de imágenes identitarias del Uruguay es un itinerario que se reformula de forma permanente y sobre el que hay una extensa bibliografía referida al siglo XIX $\mathrm{y}$ al xx, particularmente en el contexto de los festejos del Centenario.
} 
formas de producción visual como la caligráfica y especialmente la obra de Pablo Nin y González, encontramos prácticas que tuvieron un peso importante en la cultura visual de la época y en la construcción de ese imaginario.

Como señala Ernesto Beretta (2009), el estudio de la caligrafía, presente en la enseñanza primaria, no solo tuvo como fin mejorar la legibilidad del texto en tiempos en que la burocracia requeriría de escribas idóneos, sino que también tuvo un sentido formativo, en cuanto exigía una buena dosis de autocontrol y disciplinamiento. Los textos además de legibles, se transformaban muchas veces en piezas de gran belleza y exquisita ornamentación, en las que la alegoría estaba a la orden del día. Trompetas, laureles y genios alados que exaltaban triunfos, corazones rotos, calaveras que hablaban de lo efímero de la vida, acompañados por imágenes en las que era frecuente encontrar una alegoría, la representación de una divinidad pagana o la efigie de quien era homenajeado o recordado en el cuadro caligráfico. El texto se articulaba perfectamente con la imagen haciendo de la pieza caligráfica una obra singular.

Las caligrafías tuvieron diversos espacios de circulación, en ámbitos privados y públicos. En el ámbito privado cuando la obra caligráfica se regalaba a un amigo o un ser querido, presentaba el perfil del homenajeado, así como textos e imágenes que refirieran a esa relación personal con el calígrafo. Había otras caligrafías que circulaban por el espacio público, esto sucedía cuando el artista realizaba una obra con temas que exaltaban figuras públicas, temas históricos o alegorías relacionadas a la construcción de la nación. Es interesante observar que algunas de estas producciones fueron elegidas como imágenes para representar al Uruguay en exposiciones y ferias internacionales, en el entendido de que eran ejemplos de refinada cultura estética y civilización.

En tiempos de la colonia llegó a Montevideo, el calígrafo español Juan Manuel Besnes e Irigoyen (San Sebastián 1788-Montevideo, 1865). Besnes regaló a sus amigos tarjetas caligráficas en las que las imágenes alegóricas eran usadas con profusión a la vez que realizó imágenes de hombres públicos, algunas de las cuales salieron del país (Beretta 2009; Di Maggio 2017). Como señaló Horacio Arredondo (1929), los retratos que hizo Besnes de los caudillos Manuel Oribe y Fructuoso Rivera fueron ofrecidos a la Asamblea Nacional que 
no los compró, pero igualmente viajaron a París a principios de 1840 con José Ellauri, quien los llevó en misión diplomática. En la primera Exposición Universal realizada en París, en el año 1855, se enviaron cinco cuadros caligráficos de Besnes, por los que recibió una mención honorífica. ${ }^{3}$ En esa primera incursión al viejo mundo, las caligrafías ya generaron dudas en cuanto al rubro al que pertenecían, como señala Peluffo Linari (2006: 14) «... la recepción en París del material enviado por Besnes e Irigoyen merece una respuesta dubitativa: "Queda por saber - le decían en una carta- si se considerarán las obras hechas a pluma como cuadros o como objetos de industria del país"». Una de esas obras enviadas habría sido una copia de una pintura de Peter Paul Rubens y las otras modelos de letras caligráficas (Arredondo 1929).

Las obras de Besnes parecen haber sido las únicas imágenes que nuestro país envió a la primera exposición parisina. ${ }^{4}$ La presencia de piezas caligráficas tuvo una relativa constancia a lo largo del siglo XIX en eventos similares. Hubo otras cuatro exposiciones en París a lo largo del siglo XIX: 1867, 1878, 1889 y 1900, además de otras ferias similares en Viena (1873), Barcelona (1888), Buenos Aires (1882) y Chicago (1893) que convocaron a los uruguayos a enviar obras. A casi todas ellas fueron remitidas desde Uruguay piezas caligráficas que recibieron distintas menciones y fueron motivo de comentarios por parte de la prensa nacional. En las exposiciones mencionadas, se registraron obras de tres calígrafos, el mencionado Besnes e Irigoyen (París, 1855 y Buenos Aires, 1882), Ramón Irigoyen (París, 1878) y Pablo Nin y González, quien tuvo una presencia más continua (París, 1867,5 Buenos Aires, 1882; Barcelona, 1888 y París; 1889). Los países que participaban regularmente en ferias y exposiciones internacionales acostumbraban contar con un conjunto de objetos e imágenes que los representaban y cuyo envío se reiteraba en cada oportunidad. No parece haber sido el caso de Uruguay, no encontramos objetos que se reiteren de un envío a otro, con excepción del cuadro caligráfico de Nin La República Oriental

\footnotetext{
3 El Comercio del Plata. [Montevideo], enero, 24, 1 856: 3.

4 Se relevaron para el año 1855 El Comercio del Plata y La República, medios en los que se da cuenta del contenido de los envíos uruguayos y de los premios obtenidos.

5 En esa oportunidad también presentó la caligrafía Acta de Instalación del Gobierno Provisorio de 1825.La obra está actualmente en el edificio de la Intendencia de Florida. En todas las otras exposiciones la obra presentada fue La República...
} 
del Uruguay, Libre, Independiente y Constituida. ${ }^{6}$ Tampoco Uruguay tuvo un especial cuidado por el envío de obras que representaran a las Bellas Artes, aun sabiendo el peso y el prestigio que tal rubro tenía en dichos eventos, la selección parece haber sido más bien aleatoria y poco atendida. De hecho en ninguna de esas muestras hubo obras de Juan Manuel Blanes, 7 un pintor que tenía sólidos vínculos con las clases dirigentes y con actores como Domingo Ordoñana, ${ }^{8}$ responsable directo, como integrante de la Asociación Rural del Uruguay (ARU) de los envíos que hacía el Uruguay a París. La ausencia no pasó desapercibida, en especial en el envío de 1889, en que se comentaba en la prensa: «También se ha notado la falta de algún cuadro de nuestro compatriota el pintor Blanes».9 Lo curioso es que en la exposición de París de 1900, año en que Uruguay no estuvo presente, hubo una obra de Blanes, que el pintor, ya residente en Italia, envió a título personal. La pintura, en cuestión fue Mundo demonio y carne (Laroche, 1963) prácticamente el único desnudo conocido del pintor que fuera, sin embargo, como mencionamos el gran iconógrafo de la historia uruguaya.

La invitación a participar de las exposiciones se hacía de un gobierno a otro, Francia invitaba a Uruguay al través de la cancillería. En las exposiciones parisinas en las que Uruguay tuvo una presencia más destacada: 1878 y $1889,{ }^{10}$ la institución responsable de organizar el envío fue la ARU. Las noticias que aparecen en las publicaciones periódicas uruguayas relevadas, ${ }^{11}$ muestran que si

\footnotetext{
${ }^{6}$ Hubo alguna excepción, dada la cercanía temporal y espacial de la Exposición de Barcelona en 1888 y de la de París al año siguiente. Algunas obras y elementos decorativos de la sección uruguaya en la ciudad catalana se remitieron a Francia y no volvieron a Uruguay. Revista ARU. [Montevideo], diciembre, 31, 1889.

7 En 1875 Uruguay envió obras de Blanes a la Expos Internacional de Bellas Artes de Santiago de Chile. Los cuadros merecieron en general una Medalla de Segunda Clase. En 1877 se embarcaron desde Valparaíso en teoría con destino a la Exposición de Paris, cosa que no sucedió. Por otra parte, la Comisión de la Exposición hizo gestiones para enviar el Juramento de los Treinta y Tres, pero tampoco se concretó el envío. AGNuy. Archivo Blanes. Carpeta 1. Libro 1, folio 1.

8 Domingo Ordoñana (1829-1897). Estanciero promotor de las reformas modernizadoras del campo uruguayo, es uno de los fundadores de la ARU, impulsora de una legislación que condujo a la creación de marcas y señales para el ganado, código rural, alambramiento de los campos entre otras.

9 Villegas Zúñiga. De París. La Opinión Pública [Montevideo], julio, 31, 1889: 4.

${ }^{10}$ En 1889 el país tuvo un pabellón propio. Lopez Ocón (2004) señala que el número de expositores latinoamericanos en París se multiplicó por 35 entre 1855 y 1889, que fue el año de mayor presencia latinoamericana, luego la presencia disminuye.

${ }^{11}$ Para el año 1878 se consultó El Siglo (febrero a diciembre), El Bien (noviembre y diciembre), La conciliación, La Tribuna y Revista de la Asociación Rural, de estos últimos todo el año. Para 1889 se consultó El Siglo, La Opinión Pública, Revista de la Asociación Rural (todo el año).
} 
bien el Uruguay quiere presentarse como país civilizado y moderno, la gran oportunidad era la de mostrar sus productos agropecuarios con la intención de abrir mercados. Es probable que fueran estas razones por las que se dio poca atención a las obras artísticas, que por otra parte, tampoco eran abundantes en el nuestro país. ${ }^{12}$

En ese escenario, la obra de Nin resulta interesante, no solamente por la singularidad de la técnica, poco frecuente en las exposiciones universales, sino también por la propia figura del artista cuya trayectoria revela claras preocupaciones a la hora de construir esos «lugares de memoria» (Nora, 2008) desde los que armar el andamiaje de la nueva nación. Nin vio en la Exposición de París de 1867, la primera a la que se presenta, una oportunidad para mostrar una pieza que representaba al país, así como una oportunidad para legitimarse como artista en un gran escaparate parisino.

\section{Pablo Nin y González: perfil de un ciudadano}

Pablo Nin y González nació en Montevideo en 1835 y murió en la misma ciudad sesenta años después. Su padre, un catalán dedicado al comercio marítimo, llegó al Rio de la Plata, en tiempos de la colonia. Muchos años después, en 1892, Pablo recordaba orgulloso en una de las tantas cartas que escribiera a Andrés Lamas, que su padre, Juan Nin y Soler (s/d) había auxiliado a Liniers en la lucha contra los ingleses. ${ }^{13}$ Juan no llegó solo, en distintos momentos del siglo XIX vinieron también sus hermanos, entre ellos Antonio Nin y Soler (1783-1846), padre de los diplomáticos Federico Nin Reyes (1819-1896), Antonio Nin Reyes (1821-1866) y abuelo del escritor Alberto Nin Frías (18781937). La familia formó alianzas matrimoniales con integrantes del patriciado criollo, así como con inmigrantes destacados en el ámbito económico y político. Pablo se casó con Dolores Costa Suárez, nieta de Joaquín Suárez. ${ }^{14}$ Era el año

\footnotetext{
${ }_{12}$ Las publicaciones editadas por Uruguay a las Exposiciones del siglo XIX, registran muy pocos envíos de pinturas y en caso de hacerlo son obras y artistas casi desconocidos. En 1889 es el único año en que se destacan algunos nombres, Domingo Laporte, Diogenes Héquet y Federico Soneira.

${ }_{13}$ Carta de Pablo Nin y González a Andrés Lamas. Agosto. 29, 1892 MHN. Montevideo. Fondo Pablo Blanco Acevedo. Archivo Pablo Nin y González. Carpeta 4003.

14 Joaquín Suárez (1781-1868). Participó de luchas revolucionarias por la independencia y ocupó distintos cargos de Gobierno, incluso la presidencia de la República en ausencia del Gral. Fructuoso Rivera durante la Guerra Grande.
} 
1858, Suárez, quien fue padrino de la boda que se hizo por poder, tenía un prestigio político indiscutible, si bien ya estaba aquejado por las penurias económicas que lo acompañarían hasta el fin de sus días.

En un pequeño cuaderno en cuya cubierta se anuncia en letras doradas Memorias de Pablo Nin y González, ${ }^{15}$ el calígrafo consignó exclusivamente datos de su vida familiar. El casamiento con Dolores Costa Suárez en el Mirador de Suárez, el nacimiento de sus hijos Pablo y Celia, en 1859 y 1860 respectivamente, la tragedia familiar vivida en 1864 cuando murieron su tercera hija de dos años, la cuarta hija dada a luz prematuramente, como consecuencia de la viruela de la madre quien también murió poco después del parto. Los dos hijos que llegaron a la edad adulta concretaron matrimonios con familias conocidas de la sociedad uruguaya. Pablo se casó con Ventura Lavalleja, nieta del caudillo blanco Juan Antonio Lavalleja y Celia con Manuel Lussich Griffo, hermano de Antonio Lussich, escritor y armador. Pablo Nin y Gonzalez consignó con cuidado en sus Memorias el nacimiento de cada nieto, el fallecimiento de varios de ellos al nacer o pocos días después y la muerte de su nuera en el parto de su séptimo hijo, apenas ocho años después de contraído el matrimonio.

La familia Nin vivió en distintos momentos de su vida en el Mirador de Suárez, una vivienda que revestía para la familia un peso importante. Nin aclaró en las Memorias familiares que allí contrajo matrimonio y cuáles de sus hijos y nietos nacieron o fallecieron en el Mirador, una precisión que revela el peso familiar que tenía la propiedad. Luego de fallecida la longeva Margarita Suárez de Costa en 1895, madre de Dolores, su nieto Pablo Nin y Costa, ofreció el Mirador al Senado de la República para que comprara la propiedad, el mismo año en que se inauguraba el Monumento a Joaquín Suárez de Juan Luis Blanes, en la plaza central de la ciudad, la Plaza Independencia. Pablo Nin y Costa proponía la compra del Mirador no solo por el valor que tenía el inmueble dada su ubicación estratégica en la ciudad, sino además por el valor histórico del

15 Memorias de Pablo Nin y González. MHN. Montevideo. Fondo Pablo Blanco Acevedo. Archivo Pablo Nin y González. Carpeta 4004. 
sitio. El Senado resolvió afirmativamente la compra de la casa que se destinó en ese momento a establecimiento escolar. ${ }^{16}$

El linaje familiar y los símbolos fueron importantes para los Nin. En junio de 1872, Pablo Nin y González le escribía a Andrés Lamas, ${ }^{17}$ para pedirle consejo en cuanto a que acciones debía tomar la familia en relación a una distinción que el emperador del Brasil entregara a Joaquín Suárez: la Gran Cruz de Cristo. Según se desprende de la correspondencia, la familia de su esposa conservaba una caja con la cruz y una medalla de porcelana con cinta pero sin el diploma imperial que la acreditaba. ${ }^{18}$ Sabiendo que Andrés Lamas había recibido una distinción similar, Pablo consultaba a su amigo, si era cierto que debía devolverse al emperador la distinción una vez que el beneficiario había fallecido, ya que no querría la familia ser omisa al respecto. Lamas parece haber quedado un tanto desconcertado con la consulta, pero la tomó con toda la seriedad del caso y planteó la duda a la corte de Río de Janeiro.19 Preocupaciones que revelan una cierta mentalidad que valoraba la preservación de un orden de cuya continuidad se sentían responsables. Un orden en el que las formas y los símbolos son merecedores de atención y cuidado.

El archivo personal de Pablo Nin y González, conservado en el Museo Histórico, ${ }^{20}$ nos devela la vida de un hombre vinculado a las figuras destacadas de la vida política y cultural de la época. Las tarjetas de visita y la correspondencia que se conservan, dan cuenta de sus vínculos: Manuel Pagola, ${ }^{21}$

16 Cámara de Senadores. Sesión ordinaria. Asunto mandado repartir. (3, julio,1896). Tip. Escuela Artes y Oficios. El Monumento a Joaquín Suárez fue reinstalado en 1906 en la creada Plazoleta Suárez, ubicada donde fuera el Mirador de Suárez ya demolido.

17 Andrés Lamas (1817-1891), abogado, escritor, diplomático, historiador y político uruguayo, integrante del gobierno de la Defensa durante la Guerra Grande. Uno de los principales representantes del romanticismo en el Río de la Plata.

18 Correspondencia Pablo Nin y González dirigida a Andrés Lamas, junio de 1872. MHN. Montevideo. Fondo Pablo Blanco Acevedo. Archivo Pablo Nin y González. Carpeta 4007.

19 A los pocos días Juan Manuel Blanes escribe a Nin, desde Buenos Aires. Le dice que estuvo conversando con Andrés Lamas del tema de la medalla y que al no saber que responder, escribiría a la corte imperial.

Carta de Juan Manuel Blanes a Pablo Nin y González fechada en Buenos Aires, 30 de julio de 1872. MHN. Montevideo. Fondo Pablo Blanco Acevedo. Archivo Pablo Nin y González. Carpeta 4002

${ }^{20}$ Agradezco a la Prof. Laura Irigoyen que me advirtió de su existencia.

${ }^{21}$ Manuel Pagola (1828-1884), militar integró el gobierno de la defensa durante la Guerra Grande, ocupó varios cargos políticos y administrativos. 
Francisco Bauzá, ${ }^{22}$ Juan Lindolfo Cuestas, ${ }^{23}$ Carlos María Ramírez, ${ }^{24}$ Juan Iriarte Borda,25 Ängel Floro Costa,26 Juan Manuel Blanes, Andrés Lamas, Alejandro Magariños Cervantes. ${ }^{27}$

Nin y González fue una figura que actuó a lo largo del siglo XIX, desde un lugar discreto, pero con una sostenida preocupación por aportar a la construcción de una historia nacional, que exaltara sus gestas y sus héroes desde la visualidad. Como señalaba un contemporáneo «...el culto de los antiguos recuerdos históricos halla en ese ciudadano un ferviente propagandista». ${ }^{28} \mathrm{El}$ artículo de donde se desprende la frase, destacaba una iniciativa de Nin, para tallar en una gran piedra existente en la Piedra Alta, la proclama de la Independencia. La iniciativa terminó cuajando en la construcción del Monumento a la Independencia en Florida. Allí también estuvo Nin como integrante de la Comisión responsable de erigirlo, comisión integrada además por el escritor Alejandro Magariños Cervantes.29 El monumento, obra del escultor italiano Juan Ferrari, se inauguró el 19 de mayo de 1879, hecho que en sí mismo se transformó en un hito de la historia del Uruguay. Fue en esa oportunidad en que los poetas Juan Zorrilla de San Martín y Aurelio Berro leyeron sus célebres poemas laudatorios referidos a la gesta Libertadora.

${ }^{22}$ Francisco Bauzá (1849-1899). Político, escritor, docente, diplomático, historiador. Integró el sector católico del Partido Colorado.

23 Juan Lindolfo Cuestas (1837-1905). Político, ocupó varios cargos de Gobierno desde filas del partido colorado, fue presidente del Uruguay entre 1897 y 1898.

24 Carlos María Ramírez (1848-1898). Periodista, escritor y político uruguayo, integrante de una familia perteneciente al patriciado uruguayo de activa participación en la vida política.

25 Juan Idiarte Borda (1844-1897) fue un político uruguayo, integrante del Partido Colorado, presidente de la república entre 1894 y 1897 en que fue asesinado.

${ }^{26}$ Angel Floro Costa (1838-1906). Escritor y político uruguayo perteneciente al Partido Colorado se desempeñó como Senador en dos oportunidades. Periodista y polemista, expuso las ideas del positivismo.

${ }^{27}$ MHN. Montevideo. Fondo Pablo Blanco Acevedo. Archivo Pablo Nin y González. Carpetas $4003-4007$.

${ }^{28}$ Una roca histórica. La Democracia. [Montevideo], setiembre, 2, 1873: 3

29 Alejandro Magariños Cervantes (1825-1893), era diez años mayor que Pablo Nin y Gonzalez. Fue abogado, escritor, diplomático, rector de la Universidad, además de político. Sus largas estadías en Europa lo hacían un juez erudito a los ojos de los orientales y del mismo Nin. Como iremos viendo en el artículo, Nin y Magariños mantuvieron una estrecha correspondencia a lo largo de su vida. Integrante del romanticismo. 
La relación que Nin mantuvo con Andrés Lamas y con Juan Manuel Blanes, fue igualmente constante. Los tres se vieron involucrados en distintas empresas relacionadas a la construcción y rescate de imágenes. En 1871 a través de una serie de cartas con Lamas, Nin envió rectificaciones de datos históricos sobre Juan José Aguiar, que el pintor Juan Manuel Blanes pidiera a Lamas.30 En 1887, Lamas, Blanes y Nin, están de nuevo ocupados en la restauración de una serie de escudos de armas de la ciudad de Montevideo de la época colonial.31 Unos años después, en 1891, lo encontramos como vocal de la Comisión de Repatriación de los restos de los Guerreros de la Independencia. ${ }^{32}$

Nin y González fue además taquígrafo del Poder Legislativo entre 1856 y 1873, diputado por Durazno en la Legislatura de 1879, «colorado, pero de los más moderados», 33 miembro de la masonería, y creador de un exitoso sistema de marcas para el ganado. La ARU, promovió y logró con el apoyo de los gobiernos militares del siglo XIx, llevar adelante una serie de reformas que aseguraran la propiedad de tierras y ganados. La creación de un sistema de marcas único, era un reclamo que encontró solución en la propuesta de Nin.34 El sistema en cuestión, tenía el beneficio de presentar signos «armónicos que le dan una forma enteramente igual por ambos costados, lo que aparezca marcado en uno de sus lados, indica con seguridad lo que en el otro debiera figurar y se hubiese suprimido por cualquier defecto de marcación» (Nin, 1885, 5). El sistema estuvo presente a través de una publicación en la Exposición de París de 1878 y fue premiado en la Exposición Feria Paysandú en 1880 y en la Exposición Continental de Buenos Aires de 1882.

\section{Ciudadano y calígrafo}

\subsection{Primeras obras}

\footnotetext{
30 Carta de Pablo Nin y González a Andrés Lamas de enero 21,1871. AGNuy. Montevideo. Fondo documental Andrés Lamas. Caja 103. Carpeta 11.

${ }^{31}$ Correspondencia de Pablo Nin y Gonzalez a Andrés Lamas entre octubre de 1887 y enero de 1888. AGNuy. Montevideo. Fondo documental Andrés Lamas. Caja 103. Carpeta 11.

$3^{2}$ MHN. Monteideo. Fondo Pablo Blanco Acevedo. Archivo Pablo Nin y González. Carpeta 4003.

33 Perfiles. La reforma. [Montevideo], enero.1.1879

34 Nin y Gonzalez, P. (1885). Documentos relativos al estudio y examen sobre los sistemas de marcas para ganado mayor y certificados rurales inventado por Pablo Nin y González. Montevideo: Imprenta á vapor de El Siglo.
} 
En paralelo a la actividad pública que desempeñó Nin y a sus tareas como taquígrafo en el Senado, la actividad desde la que se proyectó profesionalmente fue la de calígrafo. Desde su juventud usó su destreza para producir imágenes que homenajearan figuras públicas o hechos históricos que consideraba dignos de destaque. Siempre con una fuerte intención ética y pedagógica.

Imagen 1. Pablo Nin y González. «La República Oriental del Uruguay Libre, Independiente y Constituida». 1865-66. Cuadro Caligráfico. (Gentileza: Museo Histórico Nacional. Casa de Rivera. Montevideo)

Nin fue docente de escritura en el colegio de los Padres Escolapios (Fernández Saldaña, 1945) y en la Escuela de Artes y Oficios, al menos en 1892, según consignan las cartas de felicitación que le escriben sus estudiantes. $35 \mathrm{Su}$ aprendizaje lo habría hecho, según Fernández Saldaña (1945) con el mayor calígrafo de las primeras décadas del siglo XIX, Juan Manuel Besnes e Irigoyen. Sin embargo, el artista, como veremos más adelante, se presentaba a sí mismo como autodidacta. Evidentemente fue su tarea como calígrafo la que le brindó más satisfacciones profesionales como revelan sus papeles. El Archivo Nin y

35 Cartas de estudiantes saludándolo por su onomástico. Junio 29 de 1892. MHN. Montevideo. Fondo Pablo Blanco Acevedo. Archivo Pablo Nin y González Carpeta.4007 
González, ${ }^{6}$ al que referimos varias veces en este trabajo, conserva un Álbum de recortes de prensa, 37 en el que el calígrafo conservó en riguroso orden cronológico los comentarios que se hicieron en la prensa acerca de su obra. $3^{8} \mathrm{El}$ Álbum tiene también algunas cartas y documentos referidos a su trabajo que con seguridad consideró especialmente importantes.

Las caligrafías que fueron noticias en la prensa fueron aquellas que trataron temas históricos, patrióticos o que estaban dirigidas a figuras públicas y será a ellas a las que voy a referirme. En ese sentido fue frecuente a lo largo de su vida que enviara caligrafías a personajes que se destacaban por algún acontecimiento, operación que sin duda le dio una temprana visibilidad profesional.

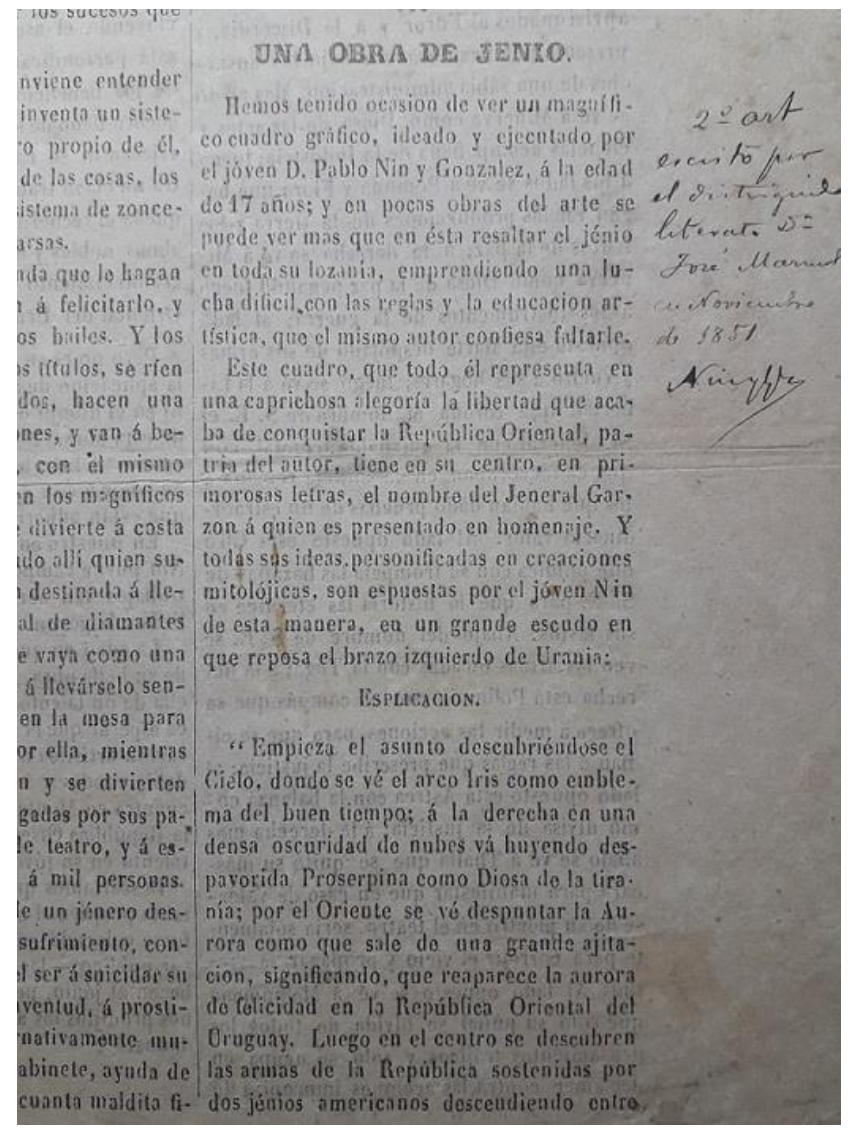

Imagen 2. Álbum. Pablo Nin y González. El calígrafo recogió en el Álbum las noticias de prensa referidas a su obra. En la que presenta la imagen, se observan las anotaciones realizadas por Nin: " $2^{\circ}$ art escrito por el distinguido literato Do. José Marmol en noviembre de 1851". Álbum. MHN. Montevideo. Fondo Pablo Blanco Acevedo. Archivo Pablo Nin y González 4002

${ }^{36}$ MHN. Montevideo. Fondo Pablo Blanco Acevedo. Archivo Pablo Nin y González 4002-4007.

37 MHN. Montevideo. Fondo Pablo Blanco Acevedo. Archivo Pablo Nin y González 4002

${ }^{38}$ Las citas a notas de prensa que se hacen en este apartado corresponden al mencionado álbum, que no registra número de páginas. Nin se preocupó sin embargo de registrar la fecha y el medio de prensa e inclusive hizo algunas anotaciones junto a los recortes, para contextualizarla. Operaciones que muestran la expectativa de que su trabajo tuviera una proyección más allá de su vida. 
Las primeras caligrafías que tuvieron una repercusión a nivel regional fueron las realizadas sobre el fin de la Guerra Grande. En febrero de 1852, terminaba un conflicto de carácter regional e internacional, que duró más de una década. El enfrentamiento culminó con el triunfo del Gral Justo José de Urquiza en la Confederación Argentina, el exilio de Juan Manuel de Rosas y una frase de compromiso que en Uruguay declaraba que no había vencidos ni vencedores, aunque en los hechos resultara vencedor el gobierno de la defensa. El escritor, político y diplomático Andrés Lamas, negoció frente a la corte imperial de Brasil, una serie de tratados, que comprometieron seriamente la soberanía uruguaya a cambio de del apoyo militar del Imperio al gobierno de la Defensa.39 En 1851, el duque de Caxías, enviado por el emperador de Brasil invadió el Uruguay, formó alianza con Urquiza y junto al general Eugenio Garzón, quien estaba al mando del ejército oriental, derrotaron a Juan Manuel de Rosas en la batalla de Caseros, forzando a la pacificación en suelo oriental. Nin y González tenía apenas 18 años y su corta vida había transcurrido en un país en guerra y en un Montevideo sitiado. Sus héroes fueron por entonces aquellas figuras a las que consideró felizmente responsables del fin de la contienda. En el campo diplomático Andrés Lamas, con quien mantuvo una cordial y constante correspondencia toda su vida, el político Joaquín Suárez con cuya nieta se casó y, en el campo militar Urquiza, Garzón y Luis Alves de Lima y Sila, duque de Caxías.

En ese escenario, es que Nin hace sus primeros retratos caligráficos que obsequió a Urquiza, Garzón y al marqués de Caxias, retratos que acompañó con de misivas en que les agradecen la paz traída al país. La operación tuvo, lo que hoy llamaríamos una cierta cobertura mediática a nivel regional. La caligrafía a Urquiza la entregó en forma personal trasladándose al palacio San José en Entre Ríos, hecho que fue recogido por la prensa uruguaya y argentina. De hecho, en su Álbum, registró que la primera vez que la prensa habló de él fue la nota que hiciera el Dr. Fermín Ferreira y Artigas, sobre esa pieza dedicada a Urquiza.40 En 1851 no era frecuente reproducir imágenes en los medios de

39 Montevideo estaba en manos de los riveristas, siendo Joaquín Suárez, como ya mencioné una de las figuras más relevantes del gobierno de la Defensa.

40 Justo J. de Urquiza. La Mariposa. [Montevideo], julio, 27, 1851: 174. 
prensa, pero las palabras podían ser suficientemente elocuentes y descriptivas.

Leamos la descripción de la alegoría a Urquiza que se publicaba en un medio argentino como El Progreso:

Empieza la composición con la perspectiva de un Palacio Gótico, en el centro del cual se eleva un monumento á la memoria del Hombre Ilustre del siglo Diez y nueve. Este monumento arranca con una laboriosa gradería. Octógona, sobre la cual se vé una media columna colosal donde descansa la bizarra figura Ecuestre del Ilustre Libertador de las Repúblicas del Plata montado en un brioso caballo, en cuya serena frente y respetable rostro, traslúcense los rasgos característicos de la nobleza y rectitud, dirijiendo á los pueblos por la senda de la felicidad. ${ }^{4}$

El Ilustre estaba acompañado por Júpiter que pisoteaba y lanzaba rayos a sus enemigos, mientras que Minerva como diosa de la paz incendiaba las armas. Una urna colocada bajo la columna representaba el lugar donde descansaban los héroes que murieron en Caseros y eran recordados con la inscripción «Culto y veneración á la memoria de los Mártires de la Libertad».

Las divinidades también acompañaron la pieza obsequiada al Gral. Garzón. ${ }^{42}$ Eran tantas las divinidades presentadas como alegorías que el artista debió registrar su explicación en la misma caligrafía, dentro de un gran medallón. Un periódico de la época registró ese texto, una cita larga que merece la pena por la precisión y la riqueza de imágenes que presenta.

I. Empieza el asunto descubriéndose el Cielo donde se vé el arco iris como emblema del buen tiempo. II. En una densa obscuridad de nubes va huyendo despavorida la discordia con sus correspondientes atributos. III. Se ve despuntar la Aurora como que sale después de una nube lúgubre y borrascosa que significa 'Que reaparece la aurora de felicidad en la República Oriental del Uruguay. IV. Descendiendo en purpúreas nubes viendo en las armas de la República iluminadas por rayos resplandores de luz y sostenidos por dos jenios americanos que significa: 'Que la República Oriental liberada aparece á la faz del Universo con todo su esplendor y Gloria. V. Más abajo se ve á Jano como árbitro de la Paz y de la Guerra el cual con motivo de la Paz ha cerrado las puertas de su templo que había tenido abiertas durante el tiempo de la guerra, se complace de tenerlas cerradas y ofrece las llaves, teniendo aprisionados al furor y a la discordia, promete una Paz duradera bajo los auspicios de una sabia administración. VI. Luego se verá Minerva como Diosa de las ciencias y las artes y a los lados Pomona y Flora que harán ver las producciones de la tierra y los frutos de la Paz. VII. Sobre la base de una media columna colosal está Minerva como Diosa de la Paz pegando fuego a los instrumentos de Guerra. VIII. Al lado opuesto está Marte despojado de sus armas y vuelto á sus hogares y las armas trocadas con la Toga. IX. La libertad que con la guirnalda triunfal corona el nombre de S.E. que es con la que condecoraban en la milia Romano a todos aquellos que habían dado pruebas de su extraordinario valor. X. Clio que con su trompeta publica las azañas de S.E. para que la historia las eternice en sus fastos.

${ }^{41}$ Cuadro caligráfico. El Progreso. [Buenos Aires], agosto, 13, 1852.

42 Palbo Nin y González. Al General en Jefe del Ejército de la República Eugenio Garzón. Cuadro caligráfico. Museo Histórico Nacional (en depósito). 
XI. Polimina que con el compás se ofrece á medir sus jestos y á moderar las acciones para que se ciñan á las reglas que describe la justicia. XII. Astrea con la balanza como Diosa de la justicia. XIII. Thaba, que se quitó su máscara para manifestar que en caso de valerse de su pectro en el teatro solo sería para corregir el vicio y propagar la virtud. XIV. Melpomene, que roto su puñal desde ese día se olvidó de todos los pensamientos trájicos y solo se ocupó en declamar contra las acciones impropias de la tiranía. XV. Urania, que con el globo celeste que sostiene en su mano pronostica á favor de la autoridad y del pueblo, las mayores felicidades, llevando con la otra un gajo de flor siempre-viva que vá simbolizad, la duración, sin la cual es incompleta la felicidad. XVI. Calíope, que transmite los hechos pasados á la historia como raro ejemplo en la posteridad. Y la memoria agradecida, personificada por una matrona coronada de ramas de enebro llenas de nebrinas, cuyas hojas ni envejecen ni se secan, y cuyo fruto no esperimenta el daño de la carcoma, empujando un clavo trabal para denotar lo fijo que queda el recuerdo del favor recibido en las almas nobles y amantes á la felicidad y engrandecimiento de la heroica República Oriental del Uruguay.43

La información exhaustiva, revela el uso de símbolos masones, así como muchos que recogen una rica tradición puesta al servicio de la alegoría y el poder, presentes en la Iconografía de Cesare Ripa44, desplegados en palacios como Versalles, donde Luis XIV vivía con estas y otras alegorías, resignificadas por la revolución francesa y puestas al servicio de la construcción de imágenes por las repúblicas latinoamericanas en el siglo XIX.

La pieza tiene importantes dimensiones $134,3 \times 102,5 \mathrm{~cm}$ y le insumió al artista 109 horas de trabajo - dato que se consigna en la propia obra- y que menciona muchas veces al presentar obras similares. Las variadas notas de prensa que se conservan en el Álbum, destacan la juventud del artista que ya mostraba gran seguridad y virtuosismo en el trazo.

La tercera caligrafía que completa el conjunto de obras dedicadas a quienes Nin consideraba héroes de la pacificación del país, fue la del duque de Caxías. Seguramente sería una pieza de menores dimensiones, basándonos en el tiempo dedicado, ya que sabemos que le insumió veinte horas de trabajo, según registra el duque en la carta en la que agradece el obsequio prometiendo exponerlo en su mejor sala. 45

\footnotetext{
43 Mensajero de Montevideo. [Montevideo], noviembre, 14, 1851.

44 Cesare Ripa publicó en 1593 un libro sobre iconología que presentó un repertorio de imágenes alegóricas asociadas en general a figuras mitológicas. La obra tuvo una enorme difusión y sentó las bases de un lenguaje alegórico ampliamente utilizado.

45 Carta del duque de Caxias firmada y con sello lacrado enviada a Nin y Gonzalez s/f. MHN. Fondo Pablo Blanco Acevedo. Archivo Pablo Nin y González Carpeta 4002.
} 
Nin ya es, a los 18 años, un artista del que se habla en la región. Las notas del Álbum continúan recogiendo elogiosas valoraciones y piezas que envía como obsequio a sus admirados héroes. El comercio del Plata, no dudó incluso en compararlo con Miguel Ángel. En 1857 se expuso en los salones de la Universidad el día de la colación de grados, un cuadro caligráfico de Nin que reproducía el Moisés de Miguel Ángel. El comentarista señaló que Nin participaba de la inspiración de Miguel Ángel y aún decía «Nuestro calígrafo ha sabido á golpe de pluma animar el Moisés, que Miguel Angel creó á golpe de cincel». 46

\subsection{La obra mayor: La República Oriental del Uruguay, Libre, Independiente y Constituida}

En 1866 dos piezas llamaron la atención del público, me refiero a los cuadros caligráficos Acta de instalación del Gobierno provisorio de 1825 y La República Oriental del Uruguay, Libre, Independiente y Constituida. Beretta (2009) señala que ambas deben haber sido pensadas como parte de un único proyecto iconográfico que exaltaba los hechos de 1825. Los héroes de la Cruzada Libertadora son registrados en La República...,47 acontecimiento que conduce a la instalación del gobierno en la Florida. Es probable que así fuera, si pensamos en las tres obras realizadas a sendos generales victoriosos en la Guerra Grande, obras autónomas y con diferentes destinatarios, pero que forman parte de un conjunto.

Me detendré en La República..., una obra de enormes dimensiones, un formato más frecuente en un cuadro histórico que en una obra de caligrafía.

Empecemos por la descripción del cuadro. Como era habitual, la República está presentada como una figura femenina, viste una túnica que deja al descubierto uno de los senos, una suerte de Marianne criollo, sin gorro frigio, pero de cabellera castaña suelta sobre su espalda (Burucúa y otros, 2009, Islas, 2016). Su mano izquierda sostiene la bandera recogida, a su izquierda encontramos un altar formado con treinta y tres piedras con los nombres de los

${ }^{46} \mathrm{El}$ Moisés de Miguel Ángel. El Comercio del Plata. [Montevideo], julio, 23, 1857.

47 Pablo Nin y González. La República Oriental del Uruguay, Libre, Independiente y Constituida, Cuadro caligráfico. 300 × 150 cm. MHN. Casa de Rivera. En exhibición.

- 58 - CLAVES. REVISTA DE HISTORIA, VOL. 7, N.o 12 (ENERO-JUNIO 2021) - ISSN 2393-6584 
Treinta y Tres Orientales y a su costado cuelga un pergamino que registra cuatro hechos históricos con sus fechas: desembarco de los Treinta y Tres, formación del Gobierno en Florida, Declaratoria de la Independencia y Jura de la Constitución. Hechos históricos que culminan con el documento máximo de la República, la Constitución abierta sobre el muro y sobre la que apoya su mano izquierda la República. La República abandonó las cadenas que aparecen a sus pies y que ya no la atan, el símbolo del comercio que siempre alude a la prosperidad económica y el yacaré, un animal autóctono del que fluye un río, completan la base del cuadro. Como sucede con los cuadros caligráficos y las alegorías, el cielo tiene que acompañar la consagración del hecho que se presenta. Un genio-niño baja del cielo consagrando la victoria, sostiene una corona de laurel y una cinta en la que se registran los nombres de las batallas ganadas por los orientales: Rincón, Ituzaingó, Misiones, Cerro, Sarandí. El nombre del cuadro aparece con letras de gran tamaño ya que como señalamos el texto y la imagen son dos elementos indisociables en la caligrafía. La historia en los años sesenta del siglo XIX, inicia un proceso de construcción positiva de la imagen de Artigas, un proceso que se iniciaba, tal vez por ello sea la gesta de 1825 la que Nin recoge en su obra. Las dimensiones del cuadro hacen que la figura se presente de tamaño natural, firme, se apoya en la bandera y la constitución, a la vez que las sostiene. Es una sólida imagen de la República.

Las notas de prensa conservadas por el propio Nin en su Álbum, 48 registran los comentarios de varios medios que al conocerla en 1867, plantearon que el gobierno debería enviar La República... a la Exposición que se está preparando en París para el año siguiente. Según señalaba uno de ellos, la obra permitiría «evidenciar allí que en la República Oriental del Uruguay hay génios que saben transmitir al papel con rasgos que harían honor al primer calígrafo del mundo, las tradiciones gloriosas de nuestra patria».49 El gobierno, a juzgar por las notas de prensa publicadas en las semanas siguientes, no solo no mostró interés en enviar el cuadro, sino que además lo devolvió al pintor aduciendo que no había lugar en la casa de gobierno para albergarlo.50 Finalmente el propio

${ }_{48}$ El Siglo [Montevideo], julio, 1, 1866; La Tribuna [Montevideo], junio, 29, 1866, El español [Montevideo], julio, 4, 1866; La opinión nacional [Montevideo], junio, 19, 1866.

49 Respeto al Superior Gobierno. La Tribuna [Montevideo], junio, 29, 1866.

${ }^{50}$ El cuadro del Sr. Nin. La opinión Nacional [Montevideo], agosto, 19, 1866. 
artista ofreció a la comisión encargada del envío uruguayo a París y el cuadro fue enviado a la capital francesa, ${ }^{1}$ junto a Acta de Instalación del Gobierno Provisorio de 1825.

Fue la consagración del Nin calígrafo, ya como artista maduro. La obra regresó y el artista editó un pequeño libro, $5^{2}$ en el que recogía documentos por demás interesantes para entender la obra en su contexto de recepción y circulación.

El primer documento que transcribe en el mismo, es una carta que le dirige Julio G. Wehner, Comisario Delegado de la República del Uruguay y miembro del Jurado internacional en la Exposición de París. En la misma, Wehner explicaba que el cuadro no había podido concursar, debido a que llegó con retraso -ya conocemos las razones- y el jurado no pudo evaluarlo. El relato de Wehner presenta dos puntos interesantes. En primer lugar, evidencia la preocupación e insistencia de Wehner por presentarlo al jurado, la misiva relata sucesivas notas y pedidos al Jurado para que lo evalúe, lo que supone trasladar la gran caligrafía a distintas salas e inclusive a la misma oficina de la Comisión Imperial. Las gestiones que ocuparon al delegado entre abril y junio fracasaron, cuando la Comisión y este es el segundo hecho interesante, le dice que la obra se había presentado en la sección equivocada. Efectivamente, el cuadro se presentó en la primera sección, dedicada a las Bellas Artes, cuando debía haberse presentado en la octava, que incluía obras: Aplicaciones del dibujo y de la plástica á las artes usuales.

El delegado uruguayo, al percatarse del error llevó la obra al jurado correspondiente pero ya se habían hecho las evaluaciones, no obstante lo cual, uno de ellos indicó que de haber llegado a tiempo probablemente hubiera merecido una medalla de plata. El público, aseguraba Wehner, fue muy elogioso con la obra, que fue colocada en un gran marco, protegida con cristal y ubicada en «una galería interior que corre alrededor del jardín en el centro de la Esposicion» (Nin y otros: 6). La obra desconcertó, era una caligrafía, pero con

${ }^{51}$ Por Decreto del Gobierno Provisorio se nombra a Julio Wehner comisario oriental en la Exposición de París de 1867. AGNuy. Consulado de Francia. Caja 289. Carpeta 157.

$5^{2}$ Nin y Gonzalez, P et al. El cuadro caligráfico de Pablo Nin y Gonzalez en la Esposicion Universal de Paris de 1867. Montevideo: Imp. Liberal. 1868 
un tratamiento de pintura histórica, con un fuerte sentido pedagógico y laudatorio de la historia patria. Wehner así lo destacó citando a un medio de prensa parisino:

\begin{abstract}
Su importante trabajo ha llamado la atención de millares de personas de todas las nacionalidades que hoy, sin duda, esparcen la fama de su nombre por todas partes; finalmente, bástele saber 'que su obra ha sido la única en su género, de tan grandioso y atrevido pensamiento, que «se ha ejecutado con la pluma, que ha figurado en la Esposicion Universal de Paris de 1867. La apreciación simpática de la prensa de Paris y la opinión unánime que se ha formado entre los concurrentes á la Esposicion, sirva á Vd, de recompensa muy justa en defecto del veredicto del Jurado» (Nin, 1868: 7).
\end{abstract}

La publicación reproduce otros documentos. En uno de ellos encontramos la firma de cinco pintores (un español, un alemán y los otros franceses) que certificaron, a pedido de Nin, la calidad del cuadro por su minuciosidad. El propio Nin agradeció en varias oportunidades a los artistas que la vieron en Montevideo y que lo alentaron a presentar la obra en la exposición (Blanes, Carbajal, Williams, Livi, Agustini, Ferrari, De Martino, así como amigos de la prensa, especialmente al «ilustrado Dr. Ferreira y Artigas que con su pluma y su palabra elocuente retempló mi espíritu desfallecido por las decepciones» (Nin, 1868: 4).

Imagen 3. Nin y Gonzalez, P. El cuadro caligráfico de Pablo Nin y Gonzalez en la Esposicion Universal de Paris de 1867. Montevideo: Imp. Liberal. 1868

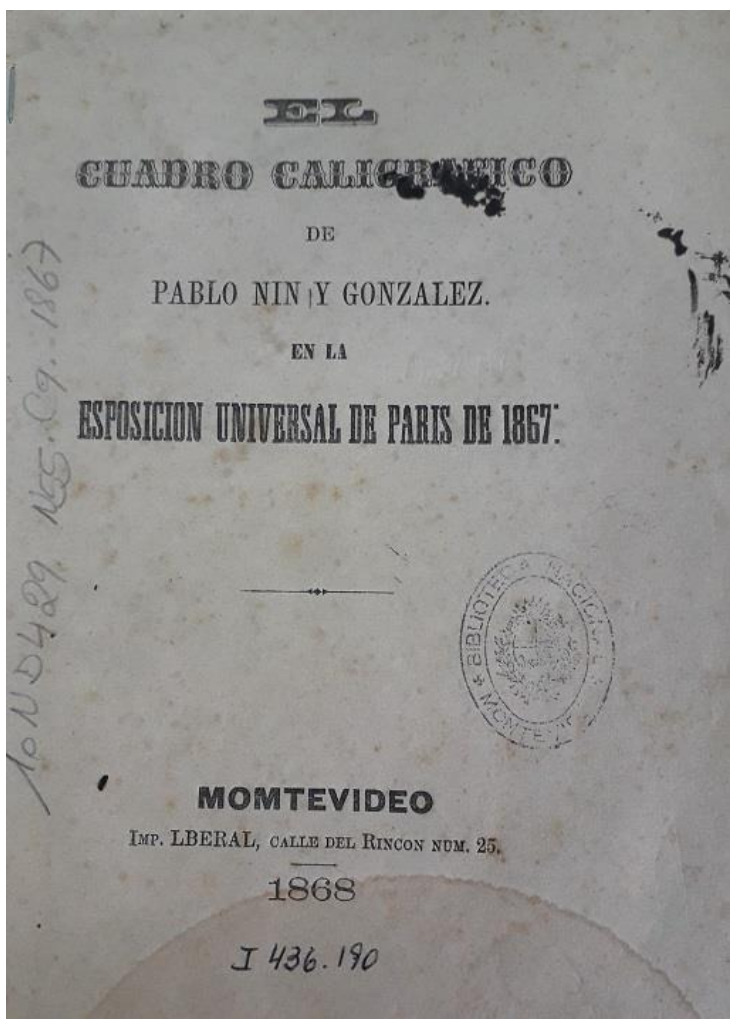


Entre las valoraciones que se hacían del cuadro, se destacó la paciencia y precisión de la obra, que le llevó no menos de dos años - otra vez el tiempo que le insumió es un valor- y que fue realizada por quien no había recibido nunca instrucción artística. Una de las tantas gestiones que hizo Wehner, es al señor De Laveley, secretario del jurado clase II, a quien le comentó: «...él se ha formado solo, sin haber tenido maestro para guiarlo, y ha llegado con todo á producir resultados verdaderamente artísticos por medios completamente originales». (Nin et alt. 1868: 8). La autodidactica fue un punto recurrente en la construcción de las biografías de los artistas (Kris y Kurz, 1982), un punto que se consideraba que daba mayor valor a su producción. La firma del cuadro dice «Concebido y trabajado por Pablo Nin y Gonzalez natural de la República Oriental sin haber tenido instrucción artística alguna. Montevideo, 20 de enero de $1867 \gg .53$

Todo el episodio nos revela datos interesantes en cuanto al lugar que tenían las imágenes en esa segunda mitad del siglo XIX. El orden que las exposiciones dieron a los productos, establecía una clara jerarquía. En todas las exposiciones francesas del siglo XIX, la primera categoría fue para las Bellas Artes y dentro de ella la pintura al óleo era el primer rubro. Las imágenes litográficas, fotográficas o caligráficas entraban en otras categorías que las asociaban a lo utilitario y por tanto las alejaban de las Bellas Artes. Las máquinas y productos manufacturados estaban antes que las materias primas y los alimentos. Claramente se establecía y explicitaba que el arte era la cumbre de la civilización y el progreso. El Uruguay envió una obra que aspiraba a ingresar en ese rubro,54 era una obra virtuosa en su ejecución manual, que por su formato y temática podía vincularse a las grandes pinturas de ideas que eran valoradas en primer orden. Sin embargo no era un óleo, sino un cuadro

53 La bibliografía consultada indica en cambio su formación con Besnes e Irigoyen, sin embargo en el extenso archivo de Nin, no hay ninguna referencia a Besnes como su maestro. De hecho el maestro al que se cita en una nota es Pedro Giralt.

54 Uruguay solo envió una pintura en la categoría Bellas Artes, una acuarela del puerto de Montevideo de Tiberghien Ackermann, cónsul uruguayo en París y responsable de la exposición. Ackermann fue el autor de la publicación que acompañaba la muestra uruguaya y que incluía una noticia histórica y un catálogo de los objetos expuestos. Ackermann, T. (1867) Exposicion universelle de 1867. Republique oriental de l'Uruguay. Notice Historique et Catalogue. Paris: Imprimerie de M. Veuve Bouchard-Huzard. 
caligráfico, una técnica que los expositores parisinos, valoraron más cercana a las producciones utilitarias. Para los uruguayos igualmente fue suficiente la promesa de una medalla de plata dada en el gran espacio de legitimación del arte por excelencia. Nin había necesitado la legitimación de otros artistas que lo alentaron a presentar la obra y el Uruguay la legitimación, o la promesa de legitimación, de un jurado francés. Las medallas, diplomas y otros reconocimientos, eran procurados con ansiedad y una de las tareas de los representantes uruguayos, era justamente asegurarse que los jurados vieran y midieran las obras enviadas.

Debemos recordar que, en 1868, los montevideanos habían tenido pocas experiencias estéticas que los enfrentaran a los grandes óleos históricos. Prácticamente la única había sido en 1867, cuando una de las grandes pinturas peruanas recaló en Montevideo de camino hacia Lima: Los funerales de Athahualpa,55 obra del Luis Montero. Montero la había pintado en Florencia y de camino hacia Lima, se detuvo en Montevideo donde estuvo expuesta en el Teatro Solís, causando un hondo impacto. Algunos cronistas aprovecharon la oportunidad para plantear las características que debía tener la pintura histórica: «belleza de composición, corrección del dibujo, valentía del colorido, riqueza de detalles, verdad histórica y expresión moral de las fisonomías» (Amigo 2000: 22). Muchas de esas características estaban presentes en la obra de Nin, por lo que La Tribuna, encontró un paralelismo entre las dos obras, porque en ambas el punto fundamental era el sentido alegórico y patriótico que ambas perseguían y la idoneidad técnica, más allá de cuál fuera la técnica elegida. 56

Montero, estuvo en nuestra ciudad y entabló relación con artistas como Blanes y Nin al que elogió su obra, destacando que no podría haber nada superior en su género. El peruano se asombró de que pudiera lograrse una obra tan singular «a pluma».57

55Los funerales de Atahualpa. 1867. Óleo/lienzo. $420 \times 600$ cm. MALI. Lima.

${ }^{6} 6$ La Tribuna [Montevideo] Noviembre 29 de 1868.

57 Domingo 21 de junio de 1868. El señor Luis Montero. El órden. [Montevideo] Junio 21 de 1868. 
La célebre obra de Juan Manuel Blanes, el Juramento de los Treinta y Tres Orientales, ${ }^{8}$ debería esperar diez años para hacer su triunfal y consagratoria puesta en escena. La primera obra consagratoria de Blanes llegó poco después de La República...., fue Un episodio de la fiebre amarilla en Buenos Aires,59 (Malosetti Costa 2003). Expuesta con gran suceso en Buenos Aires, fue inmediatamente comprada por el gobierno uruguayo. La comparación fue entonces entre Un episodio... y La República..., el periódico Los Debates afirmó que eran las dos obras maestras que hasta el momento habían realizado artistas. ${ }^{60}$

Más allá de ser una caligrafía y no un óleo, repetimos, los valores que transmitía, las dimensiones, la precisión técnica, el éxito que había logrado en la Exposición de París de 1867, la presentaban como una obra comparable con las mejores pinturas históricas del momento. Esos valores fueron los que inspiraron a Nin y los que lo llevaron a escribir sobre las obras de Blanes en la prensa. Solo se registran en su Álbum tres notas de su autoría, escritas bajo el seudónimo «Justo», las tres son referidas a las obras del pintor y amigo. La primera es justamente sobre Un episodio... y las otras dos serán en los años siguientes sobre Últimos momentos del General José Miguel Carrera, ${ }^{61}$ y el Juramento de los Treinta y Tres Orientales. Los méritos que encuentra Nin en Un episodio..., son sin duda los que también lo inspiraron a hacer La República... Dice Nin:

\begin{abstract}
iCuánta moral filosófica no se desprende de esa escena, donde el pintor, en el yunque de la meditación profunda ha sabido combinar la multitud de pensamientos á que ha dado forma á la luz de su razón!... [...] No es la pintura física de la naturaleza, que con tanta habilidad nuestro artista trata; es la pintura moral, es la pintura del sentimiento, en una palabra -la filosofía de la pintura, el razonamiento acabado, lo que allí se admira también en esa prodigiosa combinación. ${ }^{62}$
\end{abstract}

La filosofia en la pintura, no se mide solo en la destreza del artista o en la técnica que utilice, sino principalmente en sus ideas y la eficacia para

${ }^{8}$ El Juramento de los Treinta y Tres Orientales. 1878 . Óleo sobre tela, $311 \times 564 \mathrm{~cm}$. Museo Municipal de Bellas Artes Juan Manuel Blanes, Montevideo

59 Un episodio de la fiebre amarilla en Buenos Aires. Óleo sobre tela, $230 \times 180 \mathrm{~cm}, 1871$.

MNAV, Montevideo.

${ }^{60}$ Una buena idea combatida sin razón. Los debates. [Montevideo]. Noviembre, 5, 1871.

${ }^{61}$ Últimos momentos de Gral. José Miguel Carrera. 1873. Óleo sobre tela. $217 \times 292 \mathrm{~cm}$. MNAV.

${ }^{62}$ Un episodio. La Tribuna. [Montevideo], octubre, 15, 1871.

- 64 - CLAVES. REVISTA DE HISTORIA, VOL. 7, N.o 12 (ENERO-JUNIO 2021) - ISSN 2393-6584 
presentarlas. Las obras de arte. pensaban estos artistas, debían enseñar y educar en civismo

Una vez en Montevideo, Nin donó la pintura a las Cámaras Legislativas que acuñaron una medalla de oro con la inscripción «Al genio artístico, 1868» y le otorgaron una importante cifra económica. El destino de la obra fue el Museo Nacional, si bien sabemos que estuvo un tiempo expuesta en el Senado de la República. Le hicieron reproducciones fotográficas y litografías cuya venta al público le dio al calígrafo mayor visibilidad a nivel nacional. Al año siguiente como agradecimiento por la obra, un grupo de ciudadanos de Maldonado, Minas Durazno y Cerro Largo le obsequiaron a Nin una bella escribanía de plata. 63

Los viajes de La República... estaban lejos de verse culminados. En 1882 La República... se encontraba en el Museo Nacional y su director Ramón Bauzá la puso a disposición de La Liga Industrial, responsable de los envíos a la Exposición Continental de Buenos Aires.64 La caligrafía cruzó esta vez el Río de la Plata junto a dos cuadros caligráficos de Besnes e Irigoyen (Alfabeto 1 y Alfabeto 2). 65

Una vez más La República... cruzó el Atlántico en 1888 hacia la Exposición de Barcelona, donde fue merecedora de una medalla de bronce ${ }^{66}$ y al año siguiente directamente de Barcelona se dirigió a la célebre Exposición de París donde recibió de nuevo otro bronce67 En esta última, la obra no se expuso en el rubro Bellas Artes, sino en la categoría XI, destinada a las artes aplicadas. ${ }^{68}$

Un último proyecto y una última exposición. En 1892, cuando se estaba preparando una gran exposición en Chicago, conmemorativa de los cuatrocientos años del descubrimiento de América, Nin hizo una obra alusiva al

${ }^{63}$ La Tribuna. [Montevideo], enero, 30, 1869.

${ }^{64}$ Carta de Pedro Bauzá, director del Museo Nacional a la Liga industrial. Enero 28.1 de1882. MHN. Antecedentes e inventarios. Carpeta 719. folio 10).

65 MHN Antecedentes e inventarios carpeta 1049.

${ }^{66}$ Relación de Recompensas. El Siglo.[Montevideo], enero, 4, 1889.

${ }^{67}$ Revista ARU. [Montevideo], diciembre, 31, 1889: 617.

68 Exposition Universelle Internationale de 1889. Republique Oriental de L'Ururguai. Notice Historique et etatisque suivie du catalogue des exposants. Paris: Imprimerie de la Presse, 40. 
tema. Como en otras oportunidades la sometió al juicio de quienes consideraba idóneos y conservó sus respuestas en el archivo personal. Ángel Floro Costa fue uno de ellos. ${ }^{69} \mathrm{El}$ otro, su viejo amigo Alejando Magariños Cervantes, quien alentó a participar del evento, admirado de que «á su edad conserva Ud todavía con la firmeza del pulso, el vigor de la inteligencia, el calor de la inspiración, y la juventud eterna del talento, raro privilegio que muy pocos alcanzan!».70 Magariños le ofrecía publicar la reproducción de la obra en fototipia en Montevideo-Colón. La carta de Magariños, cuyo pulso tembloroso es evidente, está firmada el 15 de agosto de 1892, apenas unos meses antes de morir. La obra de Nin es descripta en una carta conservada por el calígrafo y firmada por el artista M. Mischkie quien se presenta como artista graduado en la Academia de Roma. La precisa descripción que hace, nos muestra una obra en la que el experto calígrafo sigue apelando a la alegoría, asociando en este caso a la juventud con el nuevo mundo que nace con el descubrimiento:

\begin{abstract}
El trabajo representa a una joven mujer que marcha derramando rosas sobre la tierra y un viejo al costado que representa el invierno que se aleja, en el fondo del cuadro se mira la figura espléndida de un pequeño muchacho tocador de flauta y en los aires se ve volar multitud de pájaros que dan un magnífico conjunto a á este trabajo y hacen resaltar las condiciones del artista que lo ha hecho. Es bien digno por cierto del premio que le ha hecho.

El cuadro es también una gran pieza de arte y representa un escudo de armas sobre el que se destaca la figura de Colon bajo el cual se ven cruzar en el Océano las carabelas del marino genovés. ${ }^{71}$
\end{abstract}

En marzo de 1893 Nin envía al Almirante J. H Gillis, ${ }^{72}$ una reproducción de la misma. En respuesta el norteamericano le sugirió que se la remitiera directamente a él y que dispondría de un lugar destacado en la feria.73 Efectivamente, así se hizo y llegaron nuevos reconocimientos a Nin y un nuevo

69 Carta de Ángel Floro Costa a Pablo Nin y González. Agosto 13 de 1892. MHN. Fondo Pablo Blanco Acevedo. Archivo Pablo Nin y González Carpeta 4003.

70 Carta de Alejandro Magariños Cervantes a Pablo Nin y González. Agosto 15 de 1892. MHN. Fondo Pablo Blanco Acevedo. Archivo Pablo Nin y González Carpeta 4003.

${ }^{71}$ Carta del pintor M. Mischkie al delegado uruguayo en la exposición E. M. Chucarro, Octubre 28 de 1893 MHN. Fondo Pablo Blanco Acevedo. Archivo Pablo Nin y González. Carpeta 4003.

72 El almirante norteamericano James Gillis, había estado en Montevideo en 1859 y protagonizado el salvataje a los tripulantes de la goleta Filomenta, La noticia conmovió a la opinión pública y el joven Nin, le obsequió al Almirante una composición caligráfica, con palomas y hojas de acanto incluidas, como agradecimiento. La noticia salió en la prensa, el rescate del Almirante y el gesto amable del novel calígrafo. Varias notas de prensa La prensa oriental [Montevideo], mayo, 6, 7, 8 y 9, 1859.

73 Carta James H. Gillis a Nin y Gonzalez. Marzo 2 1893. MHN. Fondo Pablo Blanco Acevedo. Archivo Pablo Nin y González Carpeta 4003. Gillis fue almirante inglés que estuvo en Montevideo hacia 1890 
premio otorgado por el Comité de Artes Liberales .74 La mencionada carta que envía el pintor Mischkie celebra la caligrafía pero lamenta que estuviera ubicada en el Pabellón de Agricultura y no en el de Bellas Artes!75

\section{A modo de cierre}

Como señala Nora Pierre (2008): «Los lugares de memoria nacen y viven del sentimiento que no hay memoria espontánea, de que hay que crear archivos, mantener aniversarios, organizar celebraciones, pronunciar elogios fúnebres, labrar actas, porque esas operaciones no son naturales» (p. 25). Pablo Nin y González integró un grupo de ciudadanos ilustrados, ocupados y preocupados por la construcción de esos lugares de memoria. Repasemos los emprendimientos en los que estuvo involucrado Nin: la construcción del Monumento a la Independencia en la Florida, la restauración de los escudos de armas de la ciudad de Montevideo, la repatriación de los restos de los guerreros de la Independencia, la conservación de una medalla otorgada por el emperador de Brasil a su suegro. En 1893, dos años antes de morir, fue nombrado como integrante de una comisión, cuyo objeto era conmemorar el aniversario del Desembarco de los Treinta y Tres, comisión que estaría integrada por «treinta y tres distinguidos y conspicuos ciudadanos».76 $\mathrm{Su}$ hijo, recibió en herencia el Mirador de Suárez y lo vendió al Parlamento como sitio que perpetuaba la figura de su abuelo Joaquín Suárez, Los espacios de sociabilidad, los gestos y los símbolos eran importantes para estos hombres.

$\mathrm{Su}$ producción como calígrafo, debe ser entendida en ese contexto histórico y cultural. Como calígrafo produjo un cuerpo de obra que tenía como objeto homenajear y consagrar figuras que consideró destacadas por los servicios brindados a la patria: Urquiza, Garzón, el duque de Caxías, o el almirante Gillis, hechos y alegorías históricas. Obras de vocación pública, para ser vistas y formar ciudadanos, pero también para presentar al calígrafo y al país en el exterior. Las Exposiciones fueron en ese sentido un escaparate excepcional

74 Museo Histórico Nacional. Montevideo. Archivo Nin y González. Carpeta 4003. Nota de Eduardo Chucarro a Pablo Nin y Gonzales. 3de febrero de 1894.

75 Carta del pintor M. Mischkie al delegado uruguayo en la exposición E. M. Chucarro, Octubre 28 de 1893 MHN. Fondo Pablo Blanco Acevedo. Archivo Pablo Nin y González. Carpeta 4003.

76 Carta de A. Palomeque a P. Nin y González. 15 de abril de 1893. MHN. Fondo Pablo Blanco Acevedo. Archivo Pablo Nin y González Carpeta 4007. 
por ser visitadas por miles de personas, que consagraban a la obra, al artista y al país. El Uruguay decimonónico contaba no solo con pocos artistas, tampoco tenía un público idóneo para evaluar las obras de arte. Las Exposiciones Universales y sus espacios dedicados a las artes plásticas fueron relatados en los medios de prensa uruguayos ya desde 1855 , pero eran palabras que describían obras que no eran vistas por los lectores. Las descripciones eran extensas y ricas, pero dejaban mucho librado a la imaginación. ¿Quién legitimaba a un artista en el Uruguay de mediados del siglo XIX?: algunos pocos intelectuales que habían viajado y visto obras, otros pintores, pero sabemos que tampoco había muchos, el público en un sentido amplio, que tampoco tenía formación ni experiencia estética. Nin necesita el respaldo de otros artistas y como dijimos solicitó que dejaran por escrito la aprobación de su obra. En ese panorama, presentar una obra en una Exposición Universal, nada menos que en París, era una aventura necesaria y peligrosa para un artista. Nin lo sabía, pero igualmente mandó La Rapública... a París. El resultado fue muy bueno, medallas, nuevos viajes y reconocimientos.

La República... fue por esas razones una producción iconográfica relevante para el Uruguay del siglo XIX, comparada con las mejores pinturas históricas que los uruguayos pudieron conocer, una obra digna de representar al país en el exterior. Una pieza absolutamente singular por su técnica, que desconcertó a pintores y jurados. La originalidad de utilizar la caligrafía en una obra cuyo tema era resuelto en generl con técnicas francamente identificables como de Bellas Artes, nos plantea el desafío de repensar la cultura visual uruguaya, con parámetros propios que no son los del simple reflejo.

\section{Obras citadas \\ 5.1. Bibliografía}

Amigo, Roberto. Tras un inca. Los Funerales de Atahualpa de Luis Montero en Buenos Aires. Buenos Aires: Telefónica. 2000

Arredondo, Horacio. Iconografía uruguaya, La obra de Juan Manuel Besnes e Irigoyen. Revista de la Sociedad de Amigos de la Arqueología. (1929) Tomo III: 6-23.

Beretta, Ernesto. Mucho más que buena letra. El arte caligráfico en Montevideo durante el siglo XIX. Montevideo: CSIC/FHCE/Fin de Siglo. 2011. 
Burucúa, José Emilio y otros Influencia de los tipos iconográficos de la Revolución Francesa en los países del Plata. en: Imagen y recepción de la Revolución Francesa en la Argentina. Comité Argentino para el Bicentenario de la Revolución Francesa. Buenos Aires: Grupo Editor Latinoamericano. 1990

De Torres, María Inés. ¿La nación tiene cara de mujer? Mujeres y nación en el imaginario letrado del siglo XIX. Montevideo: Arca. 1995

Di Maggio, Nelson. Juan Manuel Besnes e Irigoyen. Primer pintor uruguayo. Montevideo. 2017.

Fernández Saldaña, José. Diccionario uruguayo de biografías. 1810-1940. Montevideo: Amerindia. 1945

Gombrich, Ernst. Los usos de las imágenes. Estudios sobre la función social del arte y la comunicación visual. Nueva York: Phaidon. 2011. 1945.

Islas, Ariadna. Marianne no está sola. A propósito de la iconografía y el concepto de la república en la estatuaria en el Uruguay 1830-1930, ponencia presentada en el Coloquio Internacional «El lenguaje político más allá de la política. Hacia una historia de los conceptos sociales, culturales y jurídicos en los mundos ibéricos, siglos XVIII-XX», Casa de Velázquez, Madrid, 5-6 de setiembre de 2016.

Kris, Ernst y Kurz, Otto. La leyenda del artista. Madrid: Cátedra. 1982.

Laroche, Walter E. Derrotero para una historia del arte en el Uruguay. Tomo III. Los grandes valores que contribuyeron a la formación del arte pictórico nacional. Montevideo: Monteverde. 1963.

López Ocón Cabrera, Leoncio. La América Latina en el escenario de las exposiciones Universales del siglo XIX. Procesos. Revista Ecuatoriana de Historia. No. 18. Corporación Editora Nacional. 2002. 103-126.

Malosetti Costa, Laura. Juan Manuel Blanes y el lenguaje alegórico. En Peluffo Linari, G. y otros. Blanes. Dibujos y bocetos. Montevideo: IM-Museo J. M. Blanes. 1995. 18-25.

Malosetti Costa, Laura Los primeros modernos. Arte y sociedad en Buenos Aires a fines del siglo XIX. Buenos Aires: Fondo de Cultura Económica. 2003

Nora, Pierre (2008). Pierre Nora en Les lieux de mémoire. Prólogo de José Rilla. Montevideo: Ediciones Trilce.

Peluffo Linari, Gabriel. «Alegoría y utopía republicanas. Consideraciones sobre la producción alegórica en el Río de la Plata en el siglo XIX», Achugar, H., Moraña, M. Uruguay: Imaginarios culturales. Desde las huellas indígenas a la modernidad. Montevideo: Ediciones Trilce. 2000. 221254.

Peluffo Linari, Gabriel. Pedro Figari: Arte e industria en el Novecientos. Montevideo: MEC-UTU. 2006

Peluffo Linari, Gabriel y otros. Juan Manuel Blanes. La nación naciente. 1830 1901. Montevideo: IM-Museo Juan Manuel Blanes. 2001. 
Shiner, Larry. La invención del arte. Una historia cultural. Barcelona: Paidós. 2004

Von Sanden, Clara E. La imagen del Uruguay dentro y fuera de fronteras. La fotografía entre la identidad nacional y la propaganda del país en el exterior, 1866-1930. En Broquetas M. y otros. Fotografía en Uruguay. Historia y usos sociales. 1840-1930. (2012) Montevideo: CDF-IMM.

\section{Fuentes citadas.}

Ackermann, T. Exposicion universelle de 1867. Republique oriental de l'Uruguay. Notice Historique et Catalogue. Paris: Imprimerie de M. Veuve Bouchard-Huzard. 1867

Cámara de Senadores. Sesión ordinaria. Asunto mandado repartir. (3, julio 1896). Tip. Escuela Artes y Oficios. 1878 p. 159

Comisión de la Exposición. Album de la Republica O. del Uruguay compuesto para la Exposicion continental de Buenos Aires. Primer premio en la Exposición Continental. Montevideo: Imprenta y encuadernación de Rius y Becchi; 1882.

Díaz, J. J. Notice Historique et statistique suivir du Catalogue des Exposants. París. Imprimerie Brevetée Charles Flot. 1878

Exposition Universelle Internationale de 1889. Republique Oriental de L'Ururguai .Notice Historique et etatisque suivie du catalogue des exposants. Paris Imprimerie de la Presse. 1889.

Nin y Gonzalez, P. y otros. El cuadro caligráfico de Pablo Nin y Gonzalez en la Esposicion Universal de Paris de 1867. Montevideo: Imp. Liberal. 1868

Nin y González, Pablo. Documentos relativos al estudio y examen sobre los sitemas de marcas para ganado mayor y certificados rurales inventado por Pablo Nin y González. Montevideo: Imprenta á vapor de El Siglo. 1885

Roustan, Honoré. La république de l'Uruguay a ' l'Exposition universelle de Paris. 1889: Extrait des annuaires statistiques de la Ré publique avec des donne s comple mentaires. Montevideo: Tipografi' a a' Vapor de El Siglo. 1889.

Vaillant, A. La Republique oriental de l'Uruguay a l'Exposition de Vienne. Montevideo: La Tribuna. 1973.

\section{Archivos.}

AGNuy. Fondo Museo Histórico Archivo Lamas. Caja 103. Carpeta 11. Correspondencia Pablo Nin y González.

MHN. Antecedentes e inventarios. Carpeta 217 y 3875.

MHN. Fondo Pablo Blanco Acevedo. Colección Casavalle. Autógrafos Pablo Nin y González.

MHN. Fondo Pablo Blanco Acevedo. Archivo Pablo Nin y González. Carpetas 4002-4007 